\title{
Maternal behavior and the neonatal HPA axis in the Wistar Audiogenic Rat (WAR) strain: early life implications for a genetic animal model in epilepsy
}

\author{
Authors: Lívea Dornela Godoy ${ }^{l}$, Norberto Garcia-Cairasco ${ }^{1,2}$
}

Affiliations

${ }^{1}$ Physiology Department, Ribeirão Preto School of Medicine, University of São Paulo, Ribeirão Preto, SP, Brazil

${ }^{2}$ Department of Neuroscience and Behavioral Sciences, Ribeirão Preto Medical School, University of São Paulo, Ribeirão Preto, SP, Brazil

*Corresponding author: ngcairas@usp.br

Abstract:

Epileptogenesis is a multistage process and seizure susceptibility can be influenced by stress early in life. Wistar Audiogenic Rat (WAR) strain is an interesting model to study the association between stress and epilepsy, since it is naturally susceptible to seizures and present changes in the hypothalamus-pituitary-adrenal (HPA) axis activity. All these features are related to the pathogenic mechanisms usually associated to psychiatric comorbidities present in epilepsy. Therefore, the current study aimed to evaluate the neonate HPA axis function and maternal care under control and stress conditions in the WAR strain. Maternal behavior and neonate HPA axis were evaluated in Wistar and WAR strains under rest and after the presence of stressors. We observed that WAR pups present higher plasmatic corticosterone concentration as compared to Wistar pups. Although WAR dams do not show significant altered maternal behavior at rest, there is a higher latency to recover the litter in the pup retrieval test, while some did not recover all the litter. WAR dams presented similar behaviors to Wistar dams to a female intruder and maternal care with the pups in the maternal defense test. Taken together, these findings indicate that the WAR strain could show HPA axis disruption early in life and dams present altered maternal behavior under stressful events. Those alterations make the WAR strain an interesting model to evaluate vulnerability to epilepsy and its associated neuropsychiatric comorbidities.

Keywords: corticosterone, epilepsy, early life stress, maternal separation, pup retrieval test, epilepsy comorbidities

Abbreviations: $\mathrm{ABN}$ : arched back nursing posture; $\mathrm{ACTH}$ : adrenocorticotrophic hormone; CORT: corticosterone; HPA: hypothalamus-pituitary-adrenal axis; LG: Licking and Grooming; OT Oxytocin; PND: Post Natal day; WAR: Wistar audiogenic rat. 


\section{INTRODUCTION}

In many mammal species, maternal care requires the recruitment of a wide range of behavioral and physiological adaptations. Postpartum rodents are highly motivated to care for, nourish and defend pups [1]. Several experimental models that alter maternal care early in life have demonstrated how this disruption promotes stress and neuroplasticity that are related to psychopathologies [2-4].

Further evidence also points out that stress is relevant to the process of epileptogenesis, both in childhood and in adult life. Epileptogenesis is a multi-stage process, which can begin early in life and may be influenced by stress [5]. It is currently suggested that early stress may create a permanent vulnerability to the development of epilepsy [6]. The effects of stress on the brain are mediated by several types of molecules, including neurotransmitters, peptides and steroid hormones, which are candidates for mediating the influence of early life stress on general network excitability [6-8]. Only a few reports dedicated to the investigation on the impact of early life stress and were able to make the link with stress-induced epileptiform discharges, mainly in limbic regions, suggesting its possible role on the seizure propagation and contributory role on epileptogenesis [7,9-15]. None of those studies has assessed the relationship between postnatal early life stress and epilepsy in seizure prone strains, with the exception of the audiogenic and absence seizure models in WAG/Rij and absence seizure in GAERs strains [16]. Glucocorticoids play a contributory role in the epileptogenic process $[6,17,18]$, through several actions in the brain that could mediate this outcome, such as changes in the networks associated with seizures, or their direct effects on the excitability of the limbic system [5]. Therefore, hyperactivity in the hypothalamus-pituitary-adrenal axis (HPA), resulting from either stress or exogenously applied corticosterone, primes the brain for epilepsy [19].

Most experimental models study stress outcomes in pups by either limiting the resources or artificially reducing maternal care [20]. Only a few studies were able to relate the disruption early in life with epilepsy in a naturalistic way (not an artificially imposed intervention like maternal deprivation/separation, but through protocols involving a species related context and a translational perspective) $[20,21]$ or by monitoring previous maternal behavior dysregulation in models with specific genetic background [7,16,22,23]. 
In this context, we aim to study the Wistar Audiogenic Rat (WAR), an inbred strain that has been genetically selected through the mating of Wistar (sisters $\mathrm{x}$ brothers) rats that present behavioral seizures when exposed to acoustic stimuli [2426]. WAR is considered as a genetically selected reflex model, since in face of the acoustic stimulus animals present brainstem-dependent tonic-clonic seizures, and with the acoustic stimuli repetition (audiogenic kindling) is capable of propagate and recruit limbic regions [27]. In addition, during adult life, WARs show HPA axis disruption represented by hyperplasic adrenal gland, disruption of the circadian cycle for adrenocorticotrophic hormone (ACTH) secretion and higher plasma corticosterone levels in response to exogenous ACTH [28]. Moreover, animals from this strain present higher levels of anxiety [29] and depressive like-behaviors [30]. Therefore, considering that an extensive body of evidence suggests the important role of maternal care in the proper development of the central nervous system, as well as changes in maternal care associated to neurological and psychiatric disorders, we propose that the WAR strain may be an interesting model for the study of maternal care and the early life stress role in epileptogenesis and neuropsychiatric comorbidities associated with epilepsy.

\section{METHODS}

\subsection{Animals}

Wistar and WARs were acquired from the Central Animal Facility and from the Special Rat Strains Facility, respectively, both from the University of São Paulo, Ribeirão Preto Campus. Animals were kept in transparent acrylic boxes (45 x 32 x 17 $\mathrm{cm}$ ) and housed in the maintenance room of the Department of Physiology, under controlled ventilation and temperature $\left(25 \pm 2{ }^{\circ} \mathrm{C}\right)$, with a light/dark cycle of 12 hours (lights at 7:00 AM). Animals were allowed free access to water and food. This study was approved by the Ethics Committee on Animal Experimentation (CETEA) of the Medical School of Ribeirão Preto - USP (80/2014). Different litters were assigned to either hormonal or behavioral experiments.

\subsubsection{Mating, Gestation and Birth}

At 75 days of age, one male for every two nulliparous females was mated (Wistar $n=14$ and WAR $n=13$ ). Pregnancy was confirmed by checking the week following mating for: (i) vaginal plug (which is the seminal fluid from the male that prevents the female from mating with another male), (ii) significant body mass 
increase and (iii) changes in nipples. Pregnant females of each strain were kept in individual cages in conditions of controlled temperature and luminosity and maintained as previously mentioned. On the day of birth (Post natal day 0 - PD0) litters were ideally culled on eight pups with equally distributed sexes. Birth parameters such as the number of pups, sex distribution and possible malformations or miscarriages were recorded.

\subsection{Plasmatic Corticosterone at rest and after stress}

At PD12, Wistar and WAR offspring (from 2 different litters for each group) were decapitated under basal condition or after a physical stressor $(n=6-12)$. The physical stressor protocol was performed according to Godoy et al [31], in which pups received a subcutaneous (s.c.) injection of propyleneglycol volume of $0.1 \mathrm{ml}$. After injection animals were returned to their home cages. After $30 \mathrm{~min}$ the animals were decapitated and trunk blood was collected (between 8:00 AM and 9:00 AM) for plasmatic corticosterone assessment.

Briefly, plasma was separated by centrifugation at $4^{\circ} \mathrm{C}$ and was stored in a freezer at $-20^{\circ} \mathrm{C}$. The hormone concentration was determined by a radioimmunoassay protocol $[28,31,32]$.

\subsection{Maternal behavior in Wistar and WAR strain}

\subsubsection{Maternal care}

Maternal behavior (Wistar $\mathrm{n}=8$; WAR $\mathrm{n}=9$ ) was monitored for $60 \mathrm{~min}$ each, from PD1-PD9. Records occurred at regular periods, daily in the light phase period (08:00 AM - 10:00 AM). In each observation period, dam behavior (Supplementary Table 1) was recorded every 2 min (30 observations per session). Scores were calculated by dividing the behavior frequency by the total number of observations. Also, the behaviors were considered if occurred in or off the nest.

\subsubsection{Pup retrieval test}

In this test, at PD2, dams were removed from their home cage and were placed in another room for $30 \mathrm{~min}$. Meanwhile, pups were distributed in the home cage, away from the nest $[1,33]$. After this period, the dam was returned to the home cage, and behaviors were recorded on video for $30 \mathrm{~min}$. Two blind experimenters assessed the latency for retrieving the first pup, half litter and the whole litter. It is important to mention that the litter size presented a small variation (mean number of pups/litter = 7.2; Standard Deviation $=1.135$ ). 


\subsubsection{Maternal defense test}

The maternal defense test was performed at PD6. Animals were transported to the experimentation room $60 \mathrm{~min}$ before the test. Dams were confronted with a virgin and unknown intruder (from the same strain) in the home cage at the presence of the litter for $10 \mathrm{~min}[1,34]$. An experienced observer, blind to the experimental group, analyzed the video recordings. Behavioral parameters are described in Supplementary Table 2.

\subsection{Statistical analysis}

All analyses were performed with GraphPad Prism 7.0 (EUA). Hormonal data were analyzed with 2-way ANOVA (strain and stress factors). Birth and behavioral data were analyzed with Student's t-test (two-tailed) for comparison between the two groups. Maternal behaviors and time in nest from PD1-PD9 were also analyzed by 2way repeated measures ANOVA (strain and time factors). Additionally, in the pup retrieval test, Chi-square analysis of dams that fully retrieved their litter and matrix correlation (Pearson correlation coefficients between the possible pairs of variables) of dams litter size, latencies to retrieve first pup, half litter and all litter were compared. It was considered $\mathrm{p}<0.05$ as a significant difference.

\section{RESULTS}

\subsection{Mating, Gestation and Birth}

In 14 Wistar matings, 10 females gave birth, and, from those, there was one dam that presented cannibalism and was removed from the study. In 13 WAR matings, 11 females gave birth. There was cannibalism in one litter and, another dam gave birth to two pups, so both were removed from the study. Comparing the birth rate between both strains, we observed no significant difference in the number of pups at birth $(\mathrm{t}=1.61 \mathrm{df}=15 ; \mathrm{p}=0.12)$ (Figure 1$)$.

\subsection{Plasmatic Corticosterone at rest and after stress}

In the corticosterone assay, there is a significant difference for strain $(F[1,26]=$ 9.09; $\mathrm{p}=0.008)$, stress $(\mathrm{F}[1,26]=8.234 ; \mathrm{p}=0.005)$ but not for interaction $(\mathrm{F}[1,26]=$ 0.75; $\mathrm{p}=0.39$ ) (Figure 2).

\subsection{Maternal care}

All maternal and non-maternal behaviors were represented in the chart, demonstrating there is no overall difference between WAR and Wistar behavior, collapsing analysis from PD1-PD9 (Figure 3 and Supplementary Table 1). 
In Figure 4, the main maternal behaviors at PD1 and from PD1 to PD9 are represented. At PD1 there were no differences in the number of arched back nursing posture $(A B N ; t=0.04 ; d f=15 ; p=0,96)$ and time spent in the nest $(t=0.63 ; d f=15$; $\mathrm{p}=0.53$ ) (Figure 4A and 4C). However, in PD1, WAR dams exhibited higher licking and grooming (LG) when compared to Wistar ( $\mathrm{t}=2.62 ; \mathrm{df}=15 ; \mathrm{p}=0.01$; Figure 4B).

As demonstrated previously in the graph chart, during the PD1 to PD9 period (Figure $4 \mathrm{D}-\mathrm{F})$ there was no strain effect for $\mathrm{ABN}\left(\mathrm{F}_{(1,15)}=1.01 ; \mathrm{p}=0.32\right)$, LG $\left.\left(F_{(1,15}\right)=3.63 ; p=0.07\right)$ or total time in the nest $\left(F_{(1,15)}=0.095 ; p=0.76\right)$. There were no significant differences for time in $\left.\mathrm{ABN}\left(\mathrm{F}_{(8,120}\right)=1.62 ; \mathrm{p}=0.12\right), \mathrm{LG}\left(\mathrm{F}_{(8,120}\right)=0.12$; $\mathrm{p}=0.99)$ and for total time in the nest $\left(\mathrm{F}_{(8,120)}=1.72 ; \mathrm{p}=0.1\right)$ or interaction in $A B N$ $\left.\left.\left(\mathrm{F}_{(16,120}\right)=0.93 ; \mathrm{p}=0.48\right), \mathrm{LG} \quad\left(\mathrm{F}_{(16,128}\right)=1.48 ; \mathrm{p}=0.17\right)$ and total time in the nest $\left.\left(\mathrm{F}_{(16,120)}\right) 0.69 ; \mathrm{p}=0.69\right)$.

\subsection{Pup retrieval test}

In the pup retrieval test (Figure 5), WAR presented higher latencies to group the first pup $(\mathrm{t}=2.159 \mathrm{df}=8 ; \mathrm{p}=0.06$ ), reaching significance at half of the litter (Figure $5 \mathrm{~B})(\mathrm{t}=2,625 \mathrm{df}=7, \mathrm{p}=0.03)$ and whole litter retrieval (Figure 5$)(\mathrm{t}=2.473 \mathrm{df}=7$, $\mathrm{p}=0.04$ ). For instance, $80 \%$ of Wistar dams grouped the whole litter, whereas in WAR strain they were $55 \%\left(\chi^{2}=8.36, \mathrm{df}=1, \mathrm{p}=0.36\right)$. Matrix correlation showed that there are no significant differences for litter size and latency to first pup $(r=-0.32$; $\mathrm{p}=0.39)$, latency to half litter $(\mathrm{r}=0.10 ; \mathrm{p}=0.7811)$ or latency to all litter $(\mathrm{r}=0.21$; $\mathrm{p}=0.58)$.

\subsection{Maternal Defense test}

In the maternal defense test (Supplementary Figure 1), there was no significant difference in number of attacks $(t=0.87 ; \mathrm{df}=11 ; \mathrm{p}=0.66)$, latency for the first attack $(\mathrm{t}=0.73 ; \mathrm{df}=10 ; \mathrm{p}=0.47)$, aggressive behaviors $(\mathrm{t}=0.05 ; \mathrm{df}=11 ; \mathrm{p}=0.95)$ or threat behaviors $(t=0.02 ; \mathrm{df}=11 ; \mathrm{p}=0.98)$. The latency and frequency of $\mathrm{ABN}$ posture were also evaluated after the maternal defense test (Supplementary Figure 2). It was observed no significant difference in the frequency $(\mathrm{t}=1.70 ; \mathrm{df}=11 ; \mathrm{p}=0.84)$ and latency $(\mathrm{t}=0.38 ; \mathrm{df}=11 ; \mathrm{p}=0.70)$ when comparing the two strains.

\section{DISCUSSION}

In the current study we demonstrated that the dams of the WAR strain have no difference in the number of pups born, when compared to dams of the Wistar strain and there was no evidence of any malformation. Previous data from our laboratory 
confirm these findings [35]. Although WAR animals do not differ in number of born pups as compared to Wistar [35], a study from our group revealed that the WAR strain presented hyperproteinemia, hypertriglyceridemia, and embryonic losses suggesting an inadequate intrauterine condition for embryonic development and fetal viability [36]. WARs present both reduced weight at birth and reduced body weight gain during the lactation period and adulthood [28,35] and a recent study revealed a higher percentage of skeletal anomalies in fetuses compared with Wistar [36].

Compared to Wistar, animals of the WAR strain show a higher plasmatic concentration of corticosterone, irrespective of the presence of a stressor under rest eendition. Briefly, data from our laboratory have already demonstrated that, compared to Wistar, male adult WARs show many altered features in HPA axis later in life, such as increased corticosterone during the evening period, increased response to restraint stress and to ACTH stimulation; increased adrenal mass (higher fasciculata cortical layer area); and lower body mass [28]. WARs display increased anxiety- and depressive-like behaviors [30,37], and cognitive deficits [30] - behavior alterations that also have been implicated as comorbidities associated to stress system dysfunction [38], which contributes to the important discussion on epilepsy comorbidities [19,39]. The WAR strain was derived from the inbred selection of Wistar rats that basally displayed seizure susceptibility to acoustic stimulation. The various strain differences were evaluated by many research laboratories, in collaborative studies, involving other audiogenic seizure prone strains and also other models of epilepsy [27]. Studies involving the WAR strain and many of the alterations were discussed and further reviewed [27]. Considering this scenario, more components of the HPA axis must be evaluated to understand how the maternal behavior, offspring corticosterone expression compose this complex and intricate stress system in this audiogenic seizure-prone strain. Thus, our present data add to the discussion of HPA axis changes in a life-span perspective of the WAR strain.

Specific maternal behaviors during the first postnatal weeks have been associated with changes in neurodevelopment, especially HPA axis programming $[20,40]$. Manipulations that alter those components are responsible for 1) an inhibitory effect that maintains low corticosterone levels and 2) a suppressing effect that prevents the corticosterone response from being activated under stress, once the pup is capable of responding [41]. This feature is well known as Stress Hyporesponsive Period (SHRP) and is maintained by specific components of maternal care, such as 
LG and milk delivery, and maternal behavior disruption and stressful situations may contribute to disturbances in this sensitive period [42-45].

Even though there are no major differences in maternal behavior under rest conditions, we observed changes in the pup retrieval test, since WAR dams failed to group the litter, demonstrated by higher latencies to retrieve pups and not grouping the whole litter. Maternal care in the postpartum period has an important component represented by direct behaviors towards the pups associated with litter demands [4648]. In the WAG/Rij strain, an absence and audiogenic seizure prone rat strain, higher latencies to retrieve pups and fewer approaches are also detected [23]. In another strain susceptible to epilepsy, the EL mouse, changes in maternal behavior were also reported. It has been shown that in this strain, the EL females exhibited an increased latency in nestling the pups, which may also reflect a poorly adaptive response to a new environment, as well as a change in the motivational system [49].

Behavioral changes that emerge after the postpartum period are mediated by a wide variety of neurotransmitters such as dopamine and neurohormones such as oxytocin (OT) and ACTH. WARs show higher ACTH secretion [28] and previous studies from our laboratory have suggested that WARs, could present alterations in the OT system [50], which might be related to a naturally excessive grooming when exposed to a novel environment. As a consequence, it would be interesting to study neurohormonal brain circuits in WARs and verify how they contribute to specific behaviors directed to the pup care, like LG and retrieving.

Adding to the WAR maternal behavioral monitoring, we did not observe significant changes in the maternal defense test. It is important to consider that, although maternal care represents a strong relationship between the mother and the offspring, maternal aggression is an activity directed toward an adult intruder [55]. The nature of the two behaviors is different and consequently involves different neural circuits.

Thus, the importance of approaching a multifactorial view is required on studying epilepsy models [49], such as the current one with the WAR strain. Parental investment and early life stress can affect seizures and behavior in adult offspring phenotype [49]. Therefore, perspectives that include both neurodevelopment and environmental studies in genetic models, as opposed to exclusively investigating models with fully and regular developed adult animals, may provide further advances to make inferences about epileptogenesis, which is a phenomenon extremely affected 
by early life experiences [52,53].

\section{LIMITATIONS}

In this study, the corticosterone levels were assessed using two litters per group at only one time point. It would be interesting in future studies to include more time points, not only confirming this disruption in HPA axis but also evaluating corticosterone considering the circadian rhythm.

\section{CONCLUSION}

The current data indicate that the WAR strain does not show differences under rest conditions, but present maternal behaviors alterations in the face of stressful events. It is possible that the altered maternal behaviors in the WAR strain are specifically related to those directed towards the pups and are not involved with defense/aggression behavior. In addition, the WAR strain shows an increased plasmatic corticosterone concentration early in life, adding to previous data on increased HPA axis activity, which may contribute to the epileptogenic process and to stress-related psychiatric comorbidities already described in this genetically selected strain.

\section{ACKNOWLEDGMENTS}

The authors would like to thank Jose Antonio Cortes de Oliveira for the assistance with the breeding and maintenance of the WAR colony and the valuable discussions, and Palloma Beatriz Fialho Damas for helping with double blind analysis.

\section{FUNDING}

This work was funded by the National Council for Scientific and Technological Development, Coordination for Improvement of Higher Education Personnel, CAPES Finance Code 01 and PROEX-Physiology and the São Paulo Research Foundation; LDG (2014/17959-1 and 2017/11339-0) NGC (CNPq Research 305883/2014-3); NGC holds a CNPq Research Fellowship (305883/2014-3).

\section{REFERENCES}

[1] Bosch OJ, Neumann ID. Brain vasopressin is an important regulator of maternal behavior independent of dams ' trait anxiety. Proc Natl Acad Sci 2008;2008:6-11.

[2] Loi M, Koricka S, Lucassen PJ, Joëls M. Age- and Sex-Dependent Effects of Early Life Stress on Hippocampal Neurogenesis. Front Endocrinol (Lausanne) 
2014;5. doi:10.3389/fendo.2014.00013.

[3] Bath KG, Schilit A, Lee FS. Stress effects on BDNF expression: Effects of age, sex, and form of stress. Neuroscience 2013;239:149-56. doi:10.1016/j.neuroscience.2013.01.074.

[4] Champagne FA, Weaver ICG, Diorio J, Sharma S, Meaney MJ. Natural variations in maternal care are associated with estrogen receptor alpha expression and estrogen sensitivity in the medial preoptic area. Endocrinology 2003;144:4720-4. doi:10.1210/en.2003-0564.

[5] Joëls M. Stress, the hippocampus, and epilepsy. Epilepsia 2009;50:586-97. doi:10.1111/j.1528-1167.2008.01902.x.

[6] Huang L-T. Early-life stress impacts the developing hippocampus and primes seizure occurrence: cellular, molecular, and epigenetic mechanisms. Front Mol Neurosci 2014;7:8. doi:10.3389/fnmol.2014.00008.

[7] Dubé CM, Molet J, Singh-Taylor A, Ivy A, Maras PM, Baram TZ. Hyperexcitability and epilepsy generated by chronic early-life stress. Neurobiol Stress 2015;2:10-9. doi:10.1016/j.ynstr.2015.03.001.

[8] Koe AS. Early life stress as an influence on limbic epilepsy: a hypothesis whose time has come? Front Behav Neurosci 2009;3. doi:10.3389/neuro.08.024.2009.

[9] van Campen JS, Jansen FE, de Graan PNE, Braun KPJ, Joels M. Early life stress in epilepsy: A seizure precipitant and risk factor for epileptogenesis. Epilepsy Behav 2014;38. doi:10.1016/j.yebeh.2013.09.029.

[10] van Campen JS, Hessel EVS, Bohmbach K, Rizzi G, Lucassen PJ, Lakshmi Turimella S, et al. Stress and Corticosteroids Aggravate Morphological Changes in the Dentate Gyrus after Early-Life Experimental Febrile Seizures in Mice. Front Endocrinol (Lausanne) 2018;9:3. doi:10.3389/fendo.2018.00003.

[11] Koe AS, Salzberg MR, Morris MJ, O’Brien TJ, Jones NC. Early life maternal separation stress augmentation of limbic epileptogenesis: the role of corticosterone and HPA axis programming. Psychoneuroendocrinology 2014;42:124-33. doi:10.1016/j.psyneuen.2014.01.009.

[12] Salzberg M, Kumar G, Supit L, Jones NC, Morris MJ, Rees S, et al. Early postnatal stress confers enduring vulnerability to limbic epileptogenesis. Epilepsia 2007;48:2079-85. doi:10.1111/j.1528-1167.2007.01246.x.

[13] Jones NC, O'Brien TJ, Carmant L. Interaction between sex and early-life stress: Influence on epileptogenesis and epilepsy comorbidities. Neurobiol Dis 2014;72:233-41. doi:10.1016/j.nbd.2014.09.004.

[14] Kumar G, Jones NC, Morris MJ, Rees S, O’Brien TJ, Salzberg MR. Early life stress enhancement of limbic epileptogenesis in adult rats: mechanistic insights. PLoS One 2011;6:e24033. doi:10.1371/journal.pone.0024033.

[15] Salzberg M, Kumar G, Supit L, Jones NC, Morris MJ, Rees S, et al. Early Postnatal Stress Confers Enduring Vulnerability to Limbic Epileptogenesis, Epilepsia 2007;48:2079-85. doi:10.1111/j.1528-1167.2007.01246.x.

[16] Dobryakova Y V, A Dubynin V, van Luijtelaar G. Maternal behavior in a genetic animal model of absence epilepsy. Acta Neurobiol Exp (Wars) 2008;68:502-8. doi:19112473.

[17] van Campen JS, Jansen FE, de Graan PNE, Braun KPJ, Joels M. Early life stress in epilepsy: A seizure precipitant and risk factor for epileptogenesis. Epilepsy Behav 2014;38:160-71. doi:10.1016/j.yebeh.2013.09.029.

[18] Ferlisi M, Shorvon S. Seizure precipitants (triggering factors) in patients with epilepsy. Epilepsy Behav 2014;33:101-5. doi:10.1016/j.yebeh.2014.02.019. 
[19] Kanner AM, Ribot R, Mazarati A. Bidirectional relations among common psychiatric and neurologic comorbidities and epilepsy: Do they have an impact on the course of the seizure disorder? Epilepsia Open 2018;3:210-9. doi:10.1002/epi4.12278.

[20] Walker, Claire-Dominique; Bath, Kevin G.; Joels, Marian; Korosi, Aniko; Larauche, Muriel; Lucassen, Paul J.; Morris, Margaret J.; Raineki, Charlis; Roth, Tania L.; Sullivan, Regina M.; Taché, Yvette; Baram TZ. Chronic early life stress induced by limited bedding and nesting (LBN) material in rodents: critical considerations of methodology, outcomes and translational potential. Stress 2017;20:5,:421-448.

[21] Molet J, Maras PM, Avishai-Eliner S, Baram TZ. Naturalistic rodent models of chronic early-life stress. Dev Psychobiol 2014;56:1675-88. doi:10.1002/dev.21230.

[22] Dobryakova Y V, Belyaeva YA, Stovolosov IS, Dubynin VA, Kamenskii AA. Activation of maternal behavior of albino rats after combined treatment with dopamine and opioid receptor antagonists in low doses. Bull Exp Biol Med 2006;142:161-4.

[23] Dobryakova Y V, Dubynin VA, Luijtelaar G van. The effect of haloperidol on maternal behavior in WAG/Rij rats and its consequences in the offspring. Acta Neurobiol Exp (Wars) 2011;71:339-47.

[24] Garcia-Cairasco N, Doretto MC, Prado RP, Jorge BP, Terra VC, Oliveira JA. New insights into behavioral evaluation of audiogenic seizures. A comparison of two ethological methods. Behav Brain Res 1992;48:49-56.

[25] Doretto MC, Fonseca CG, Lôbo RB, Terra VC, Oliveira JAC, Garcia-Cairasco N. Quantitative study of the response to genetic selection of the Wistar audiogenic rat strain (WAR). Behav Genet 2003;33:33-42.

[26] Dutra Moraes MF, Galvis-Alonso OY, Garcia-Cairasco N. Audiogenic kindling in the Wistar rat: A potential model for recruitment of limbic structures. Epilepsy Res 2000;39:251-9.

[27] Garcia-Cairasco N, Umeoka EHL, Cortes de Oliveira JA. The Wistar Audiogenic Rat (WAR) strain and its contributions to epileptology and related comorbidities: History and perspectives. Epilepsy Behav 2017;71:250-73. doi:10.1016/j.yebeh.2017.04.001.

[28] Umeoka EHL, Garcia SB, Antunes-Rodrigues J, Elias LLK, Garcia-Cairasco N. Functional characterization of the hypothalamic-pituitary-adrenal axis of the Wistar Audiogenic Rat (WAR) strain. Brain Res 2011;1381:141-7. doi:10.1016/j.brainres.2011.01.042.

[29] Garcia-Cairasco N, Oliveira JA, Wakamatsu H, Bueno ST, Guimarães FS. Reduced exploratory activity of audiogenic seizures susceptible Wistar rats. Physiol Behav 1998;64:671-4.

[30] Castro GP, Medeiros D de C, Guarnieri L de O, Mourão FAG, Pinto HPP, Pereira GS, et al. Wistar audiogenic rats display abnormal behavioral traits associated with artificial selection for seizure susceptibility. Epilepsy Behav 2017;71:243-9. doi:10.1016/j.yebeh.2015.08.039.

[31] Godoy LD, Umeoka EHL, Ribeiro DE, Santos VR, Antunes-Rodrigues J, Joca SRL, et al. Multimodal early-life stress induces biological changes associated to psychopathologies. Horm Behav 2018;100:69-80. doi:10.1016/j.yhbeh.2018.03.005.

[32] Elias LLK, Dorival Campos A, Moreira AC. The Opposite Effects of Shortand Long-Term Salt Loading on Pituitary Adrenal Axis Activity in Rats. Horm 
Metab Res 2002;34:207-11. doi:10.1055/s-2002-26711.

[33] Klampfl SM, Neumann ID, Bosch OJ. Reduced brain corticotropin-releasing factor receptor activation is required for adequate maternal care and maternal aggression in lactating rats. Eur J Neurosci 2013;38:2742-50. doi:10.1111/ejn.12274.

[34] Bosch OJ, Neumann ID. Both oxytocin and vasopressin are mediators of maternal care and aggression in rodents: From central release to sites of action. Horm Behav 2012;61:293-303. doi:10.1016/j.yhbeh.2011.11.002.

[35] Umeoka EH, Eiras MC, Viana IG, Giorgi VS, Bueno A, Damasceno DC, et al. Maternal reproductive performance and fetal development of the Wistar Audiogenic Rat (WAR) strain. Syst Biol Reprod Med 2018:1-8. doi:10.1080/19396368.2018.1483443.

[36] Moraes-Souza RQ, Sinzato YK, Antunes BT, Umeoka EHL, Oliveira JAC, Garcia-Cairasco N, et al. Evaluation of Maternal Reproductive Outcomes and Biochemical Analysis from Wistar Audiogenic Rats (WAR) and Repercussions in Their Offspring. Reprod Sci 2020. doi:10.1007/s43032-020-00236-0.

[37] Garcia-Cairasco N, Oliveira J a, Wakamatsu H, Bueno ST, Guimarães FS. Reduced exploratory activity of audiogenic seizures susceptible Wistar rats. Physiol Behav 1998;64:671-4. doi:S0031938498001292 [pii].

[38] Lupien SJ, McEwen BS, Gunnar MR, Heim C. Effects of stress throughout the lifespan on the brain, behaviour and cognition. Nat Rev Neurosci 2009;10:43445. doi:10.1038/nrn2639.

[39] Kanner AM. Can neurobiological pathogenic mechanisms of depression facilitate the development of seizure disorders? Lancet Neurol 2012;11:1093102. doi:10.1016/S1474-4422(12)70201-6.

[40] van Bodegom M, Homberg JR, Henckens MJAG. Modulation of the Hypothalamic-Pituitary-Adrenal Axis by Early Life Stress Exposure. Front Cell Neurosci 2017;11. doi:10.3389/fncel.2017.00087.

[41] Levine S. Primary social relationships influence the development of the hypothalamic-pituitary-adrenal axis in the rat. Physiol Behav 2001;73:255-60. doi:10.1016/S0031-9384(01)00496-6.

[42] Suchecki D, Mozaffarian D, Gross G, Rosenfeld P, Levine S. Effects of maternal deprivation on the ACTH stress response in the infant rat. Neuroendocrinology 1993;57:204-12. doi:10.1159/000126361.

[43] Suchecki D, Nelson DY, Van Oers H, Levine S. Activation and inhibition of the hypothalamic-pituitary-adrenal axis of the neonatal rat: effects of maternal deprivation. Psychoneuroendocrinology 1995;20:169-82.

[44] Suchecki D, Rosenfeld P, Levine S. Maternal regulation of the hypothalamicpituitary-adrenal axis in the infant rat: the roles of feeding and stroking. Brain Res Dev Brain Res 1993;75:185-92.

[45] Suchecki D. Maternal regulation of the infant's hypothalamic-pituitary-adrenal axis stress response: Seymour 'Gig' Levine's legacy to neuroendocrinology. J Neuroendocrinol 2018;30:e12610. doi:10.1111/jne.12610.

[46] Rosenblatt JS. The development of maternal responsiveness in the rat. Am J Orthopsychiatry 1969;39:36-56.

[47] Mattson BJ, Williams S, Rosenblatt JS, Morrell JI. Comparison of two positive reinforcing stimuli: pups and cocaine throughout the postpartum period. Behav Neurosci 2001;115:683-94.

[48] Pereira M, Morrell JI. The changing role of the medial preoptic area in the regulation of maternal behavior across the postpartum period: facilitation 
followed by inhibition. Behav Brain Res 2009;205:238-48. doi:10.1016/j.bbr.2009.06.026.

[49] Bond TL., Drage M, Heinrichs SC. Seizure-prone EL mice exhibit deficits in pup nursing and retrieval assessed using a novel method of maternal behavior phenotyping. Epilepsy Behav 2003;4:57-64. doi:10.1016/S15255050(02)00645-5.

[50] Marroni SS, Santos VR, Castro OW, Tejada J, Santos J, de Oliveira JAC, et al. Oxytocin, Compulsion and Epilepsy: Insights from a Complex Behavioral and Neuronal Networks Association. BioRxiv 2019:638452. doi:10.1101/638452.

[51] Giovenardi M, Padoin MJ, Cadore LP, Lucion AB. Hypothalamic paraventricular nucleus modulates maternal aggression in rats: effects of ibotenic acid lesion and oxytocin antisense. Physiol Behav 1998;63:351-9.

[52] Carlier M, Roubertoux P, Cohen-Salmon C. Differences in patterns of pup care in Mus musculus domesticus I-Comparisons between eleven inbred strains. Behav Neural Biol 1982;35:205-10. doi:10.1016/S0163-1047(82)91213-4.

[53] Cameron NM. Maternal Programming of Reproductive Function and Behavior in the Female Rat. Front Evol Neurosci 2011;3. doi:10.3389/fnevo.2011.00010.

[54] Klampfl SM, Brunton PJ, Bayerl DS, Bosch OJ. Hypoactivation of CRF Receptors , Predominantly Type 2, in the Medial-Posterior BNST Is Vital for Adequate Maternal Behavior in Lactating Rats. J Neurosci 2014;34:9665-76. doi:10.1523/JNEUROSCI.4220-13.2014. 
bioRxiv preprint doi: https://doi.org/10.1101/2021.01.11.426211; this version posted January 12, 2021. The copyright holder for this preprint (which was not certified by peer review) is the author/funder, who has granted bioRxiv a license to display the preprint in perpetuity. It is made available under aCC-BY-NC-ND 4.0 International license. 
Supplementary Table 1. Parameters considered on behavioural assessment of Maternal Care, adapted from [54]. The means \% of time of all behaviors from P1-P9 represented in Figure 3 are detailed

\begin{tabular}{|c|c|c|}
\hline Observation of Maternal care (P1-P9) & Wistar (Mean\%) & WAR (Mean\%) \\
\hline arched back nursing posture (ABN) & 62 & 57 \\
\hline licking grooming (LG) & 5 & 1 \\
\hline Hovering (HOV) & 2 & 7 \\
\hline self grooming (SG) in nest & 5 & 8 \\
\hline sleeping (SLEEP) in nest & 8 & 2 \\
\hline locomotion (LOC) & 3 & 5 \\
\hline self grooming (SG) off nest & 5 & 7 \\
\hline sleeping (SLEEP) off nest & 2 & 2 \\
\hline Eating (EAT) & 8 & \\
\hline Drinking (DRINK) & 2 & \\
\hline
\end{tabular}

Supplementary Table 2. Parameters considered on Pup Retrieval and Maternal Defense tests.

\begin{tabular}{|l|l|}
\hline \multicolumn{1}{|c|}{ Pup Retrieval Test } & \multicolumn{1}{c|}{ Maternal Defense Test } \\
\hline $\begin{array}{l}\text { Latency for recovery of the first } \\
\text { pup }\end{array}$ & total number of attacks \\
\hline Latency for recovery of half litter & latency for the first attack \\
\hline Latency for recovery of half litter & Aggressive behaviors that include contact with the intruder or biting \\
\hline & Lateral and vertical threat \\
\hline & Latency and \% ABN after the end of test \\
& \\
\hline
\end{tabular}




\section{Figure Captions}

Figure 1. Birth parameters from Wistar and WAR nulliparous dams $(n=8-9)$. A. Number of pups at birth (Mean \pm SEM $10.38 \pm 1.6$ and $7 \pm 0.9$, respectively). B. Offspring sex distribution. (Mean \pm SEM for Wistar males $50.2 \% \pm 7.3$ and females $49.8 \% \pm 7.4$; Mean \pm SEM for WAR males $63 \% \pm 7.8$ and females $37 \% \pm 6.8$ ).

Figure 2. Plasmatic corticosterone concentration in Wistar and WAR rats under rest (grey) or 30 min after a physical stressor (black) ( $n=4-12$ per group). There is a significant difference for strain and for stress $(* * p<0.01)$, but not for interaction. Under rest (Mean \pm SEM) for Wistar $(0.55 \pm 0.06)$ and WAR $(1.98 \pm 0.34)$. After stressor (Mean \pm SEM) for Wistar $(2.04 \pm 0.32)$ and WAR $(2.81 \pm 0.73)$.

Figure 3. Representative graph of the mean of all behaviors in Wistar (left) and WAR strain (right) from PD1 to PD9 $(n=8-9)$. Dark blue behaviors occurred in the nest and taller light blue off the nest. ABN-Arched back nursing; LG-Licking Grooming; HOV-Hovering; SG-Self grooming; SLEEP-sleeping; LOC-locomotion; EAT-eating; DRINK-drinking.

Figure 4. Maternal behaviors in Wistar (white) and WAR (black) strains under undisturbed conditions in their home cage on PD1 (left column) and during PD1-to PD9 period (right). A,D. Arched Back Nursing (ABN) posture. B,E. Licking and Grooming (LG). C,F. Dam in the nest. At PD1 (Mean \pm SEM) for Wistar and WAR, respectively in $\mathrm{ABN}(57 \pm 5$ and $61 \pm 5)$; $\mathrm{LG}(3 \pm 1.4$ and $9 \pm 1.8)$; Dam in nest ( $84 \pm$ 6 and $80 \pm 9$ ); ${ }^{*}$ < $<0.05$ compared to Wistar at PD1. From PD1-to PD9 period (right) there is no significant difference for strain, time, nor for interaction $(n=8-9)$.

Figure 5. Behavioural assessment of Wistar (white) and WAR (black) dams in pup retrieval test. A. Latency to retrieve the first pup (Mean \pm SEM) for Wistar and WAR, respectively $(116 \pm 42$ and $535 \pm 152)$. B. Latency to retrieve half litter (Mean \pm SEM) for Wistar and WAR, respectively $(131 \pm 39$ and $564 \pm 142)$. C. Latency to group all the litter (Mean \pm SEM) for Wistar and WAR, respectively (182 \pm 70 and $713 \pm 181) .{ }^{*} \mathrm{p}<0.05$ compared to Wistar.

Supplementary Figure 1. Evaluation of Wistar (white) and WAR (black) dams behaviors in maternal defense test, upon exposure to unknown virgin untruder in the homecage $(n=8-9)$. A. Attack Behavior (Mean \pm SEM) for Wistar and WAR, respectively $(1.5 \pm 0.5$ and $2.2 \pm 0.5)$ B. Latency for first attack (Mean \pm SEM) for Wistar and WAR, respectively $(180 \pm 62$ and $262 \pm 59)$ C. Aggressive behavior (Mean \pm SEM) for Wistar and WAR, respectively $(13 \pm 2.5$ and $13 \pm 2)$ D. Threat Behavior (Mean \pm SEM) for Wistar and WAR, respectively $(9 \pm 3$ and $9 \pm 1.8)$.

Supplementary Figure 2. Evaluation of Wistar (white) and WAR (black) Arched Back Nursing $(A B N)$ after maternal defense test $(n=8)$. A. Latency (Mean $\pm S E M)$ for Wistar and WAR, respectively ( $35 \pm 7$ and $33 \pm 5$ ) and B. Frequency (Mean \pm SEM) for Wistar and WAR, respectively ( $40 \pm 11$ and $38 \pm 6$ ). 

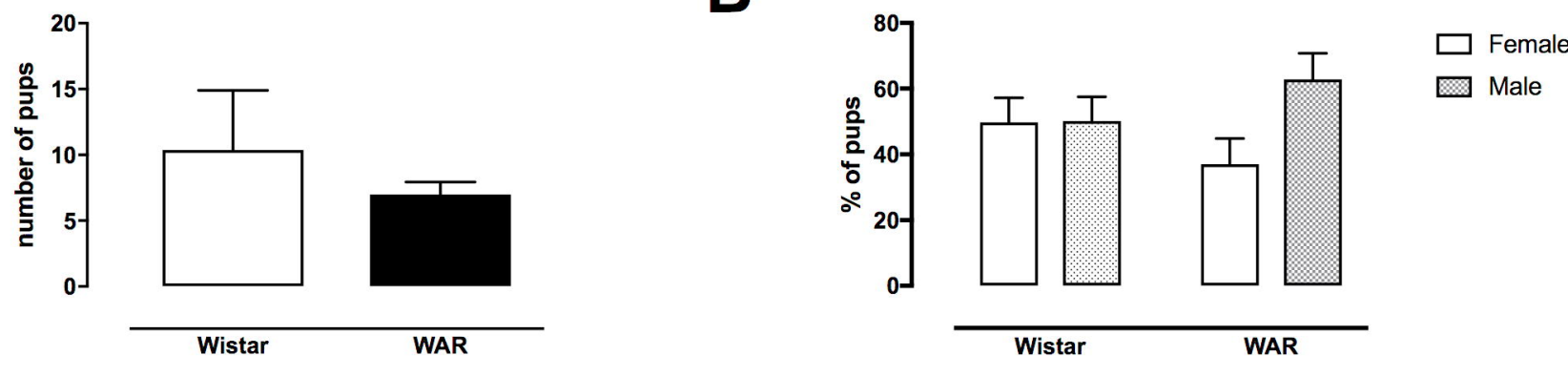


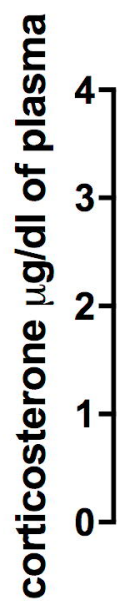

** stress

${ }^{* *}$ strain

PD12

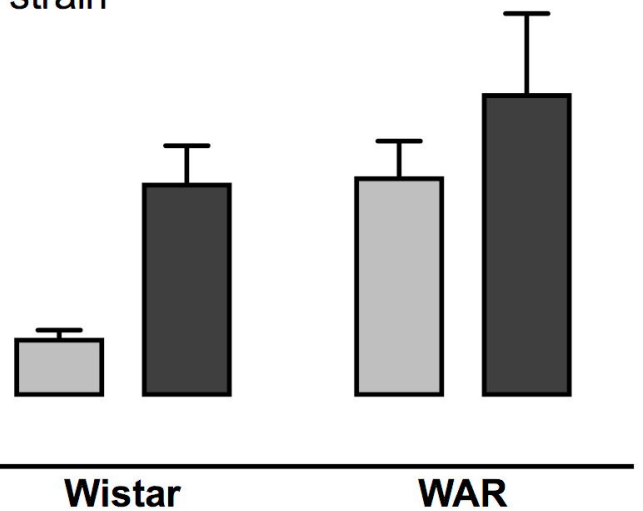

$\square$ under rest

$\square$ after stressor 


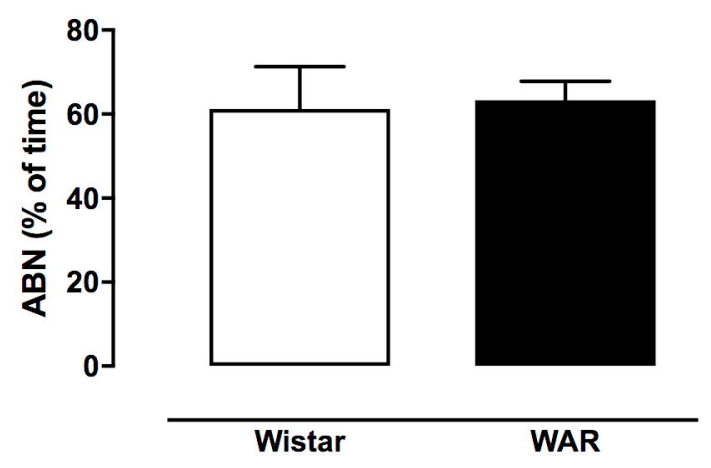

D

PD1- 9

B

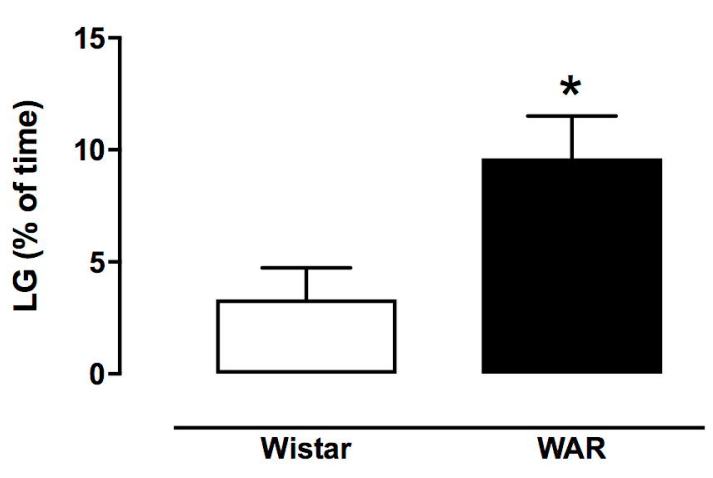

C
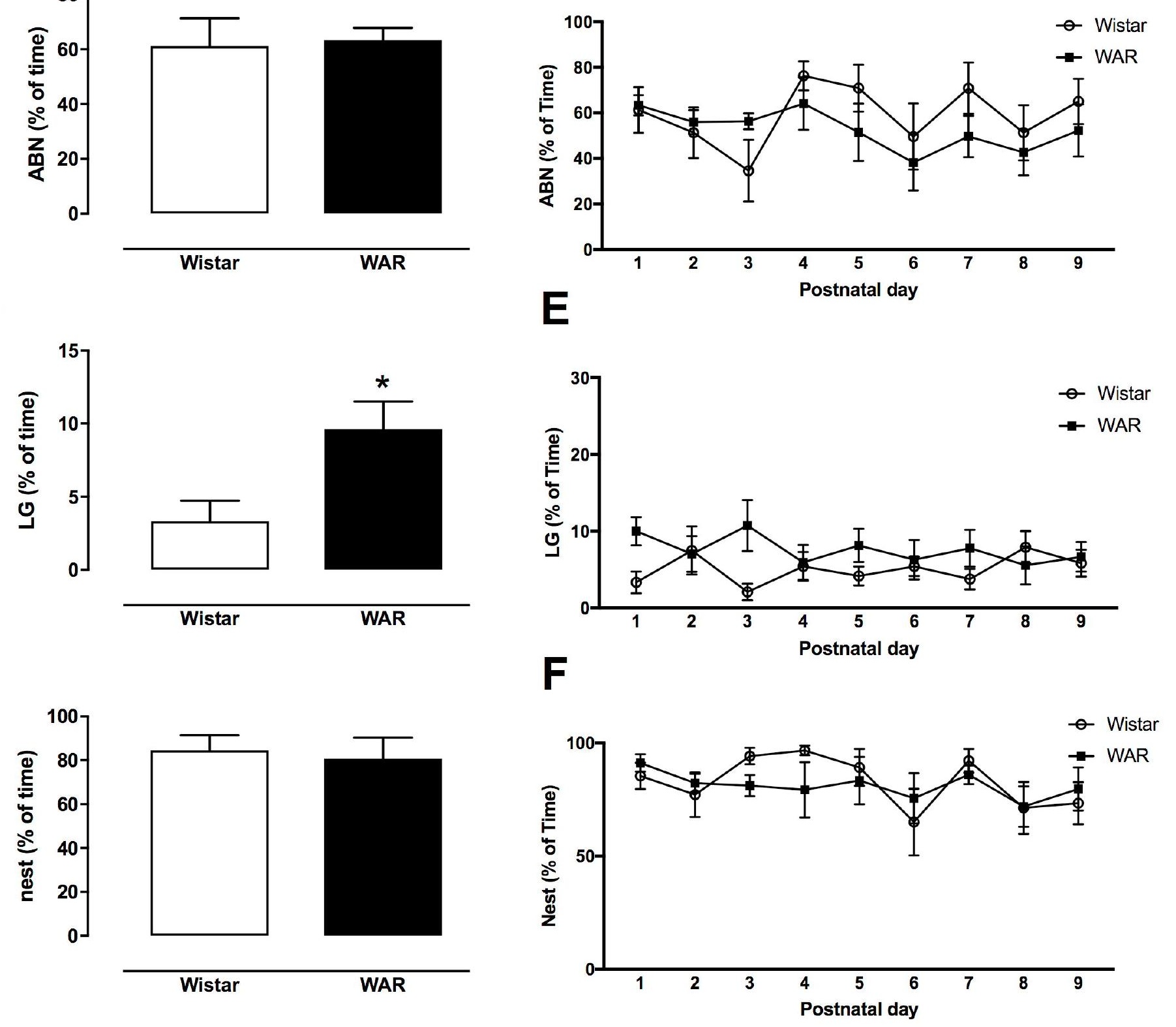
1st pup retrieval
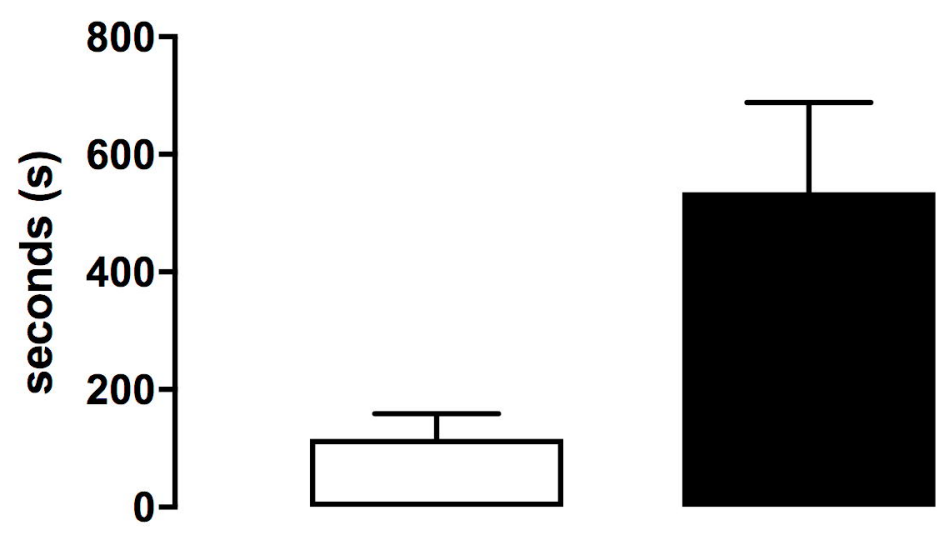

half litter retrieval
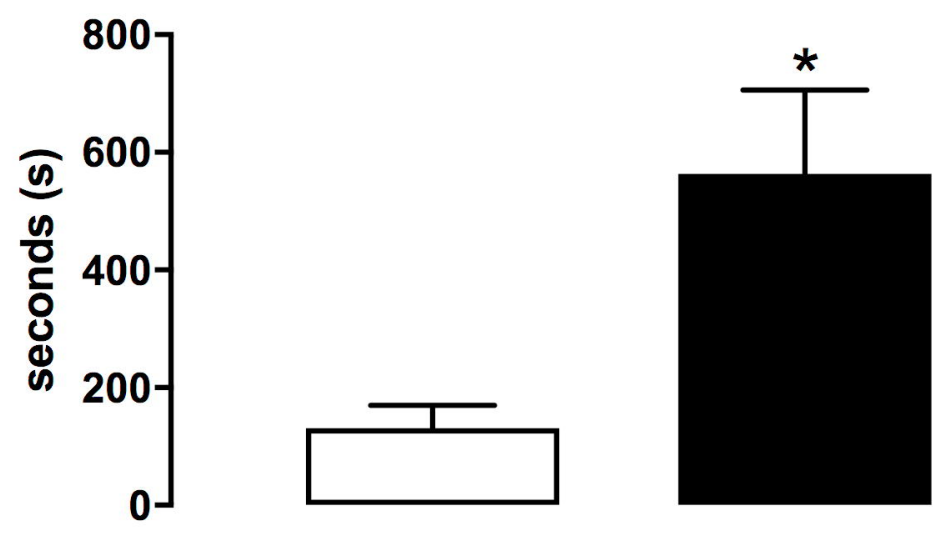

all litter retrieval
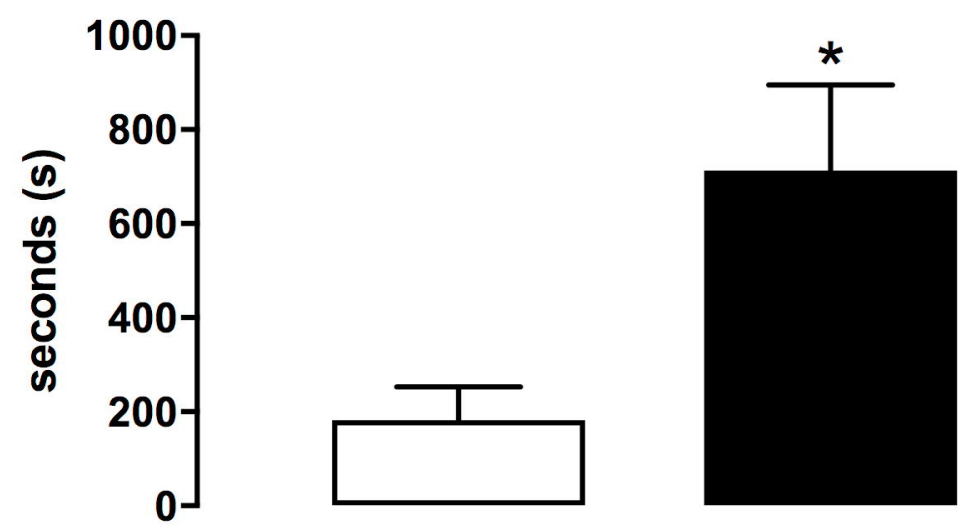
Attacks

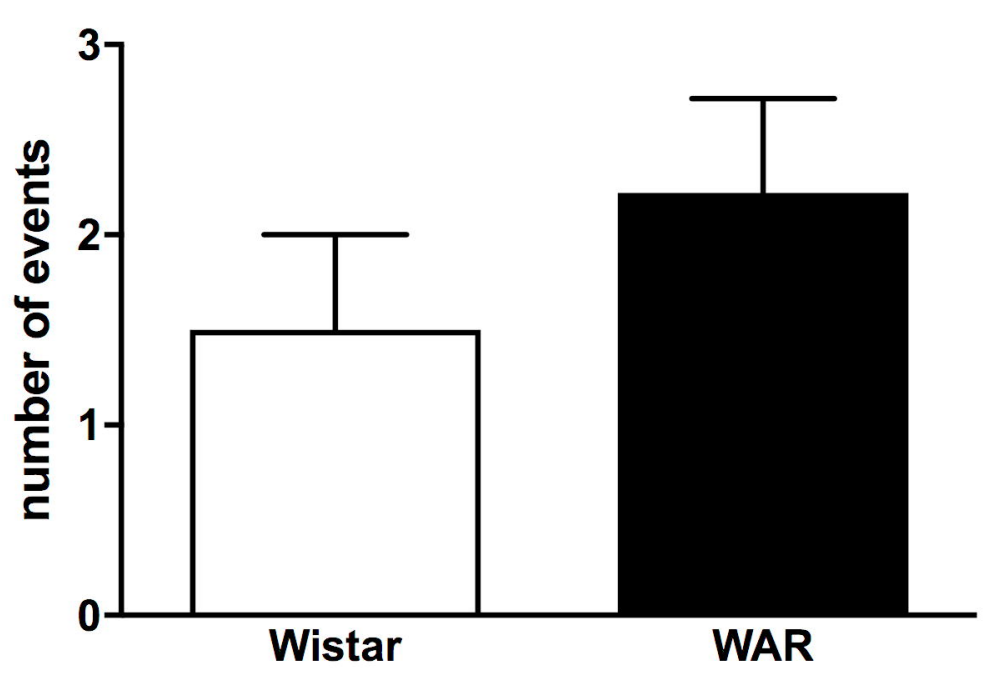

Total aggressive behaviors

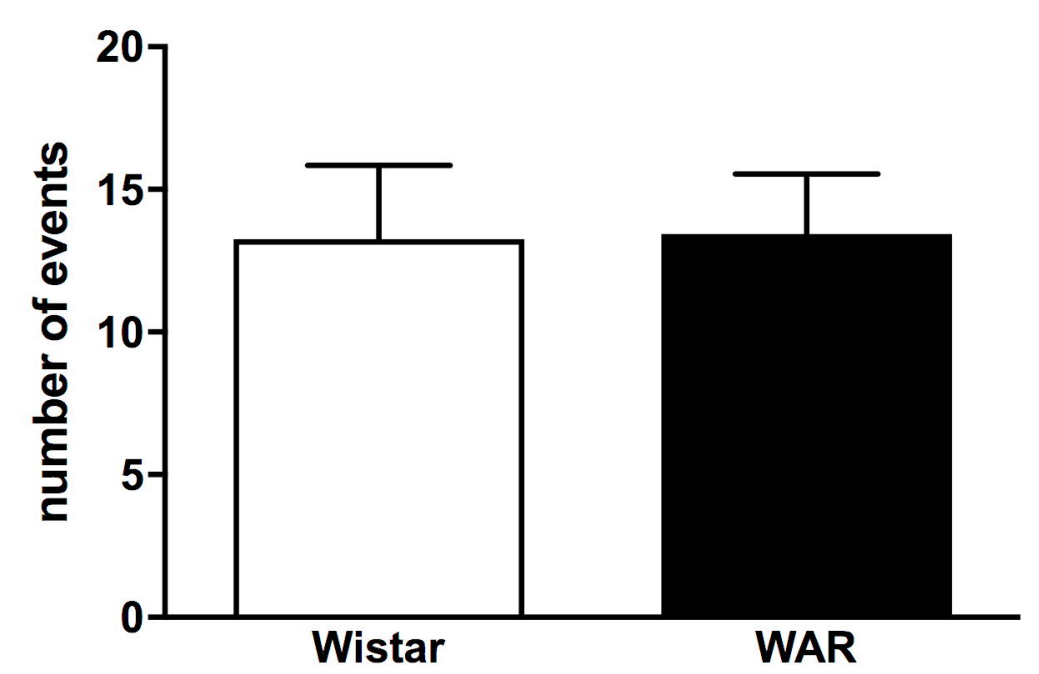

Latency to Attacks

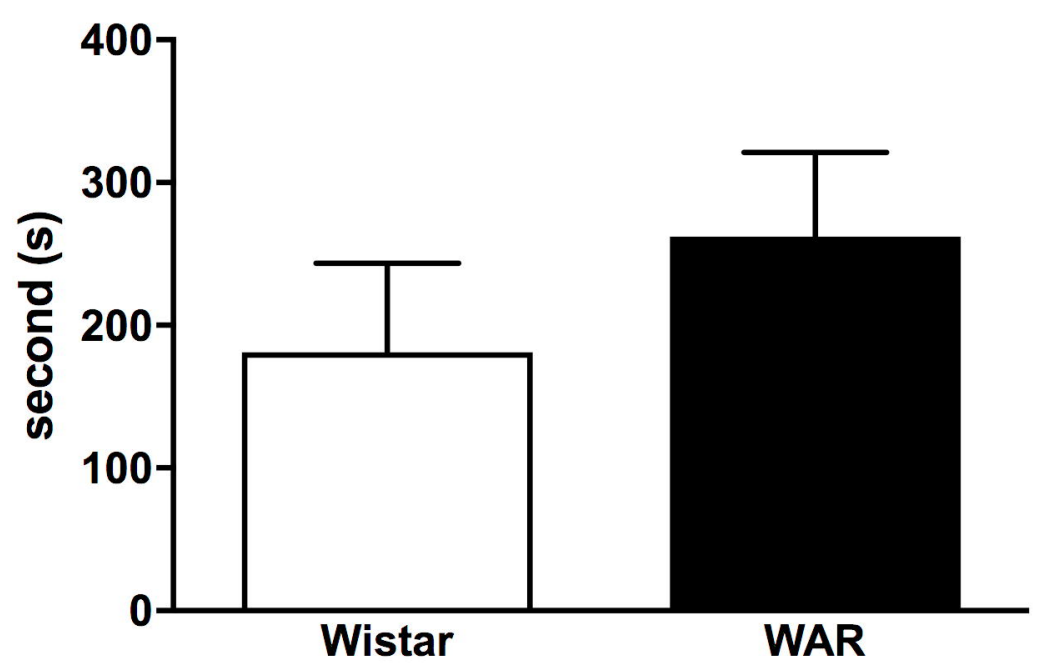

Total threats

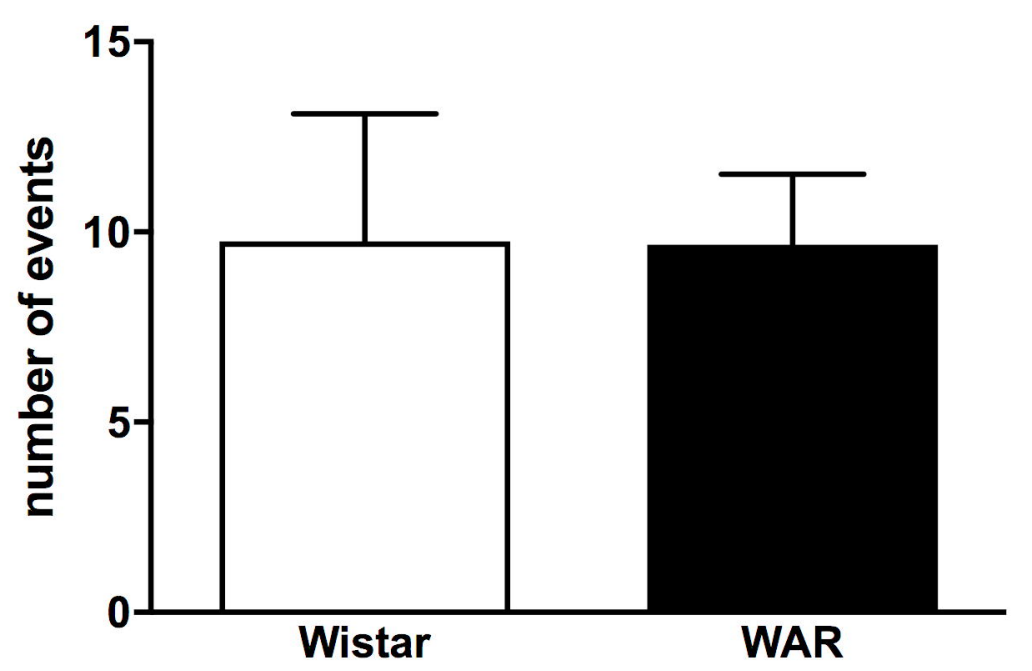


A
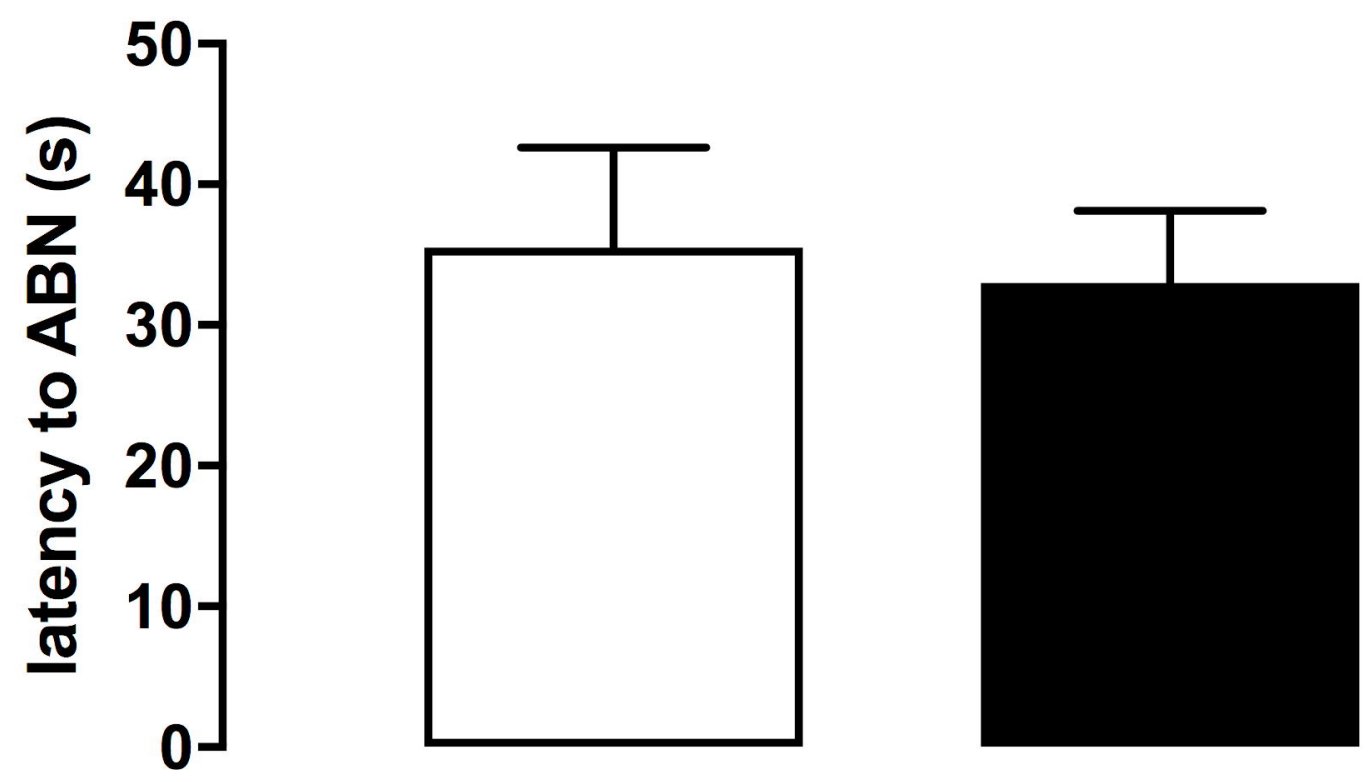

Wistar

\section{WAR}

B
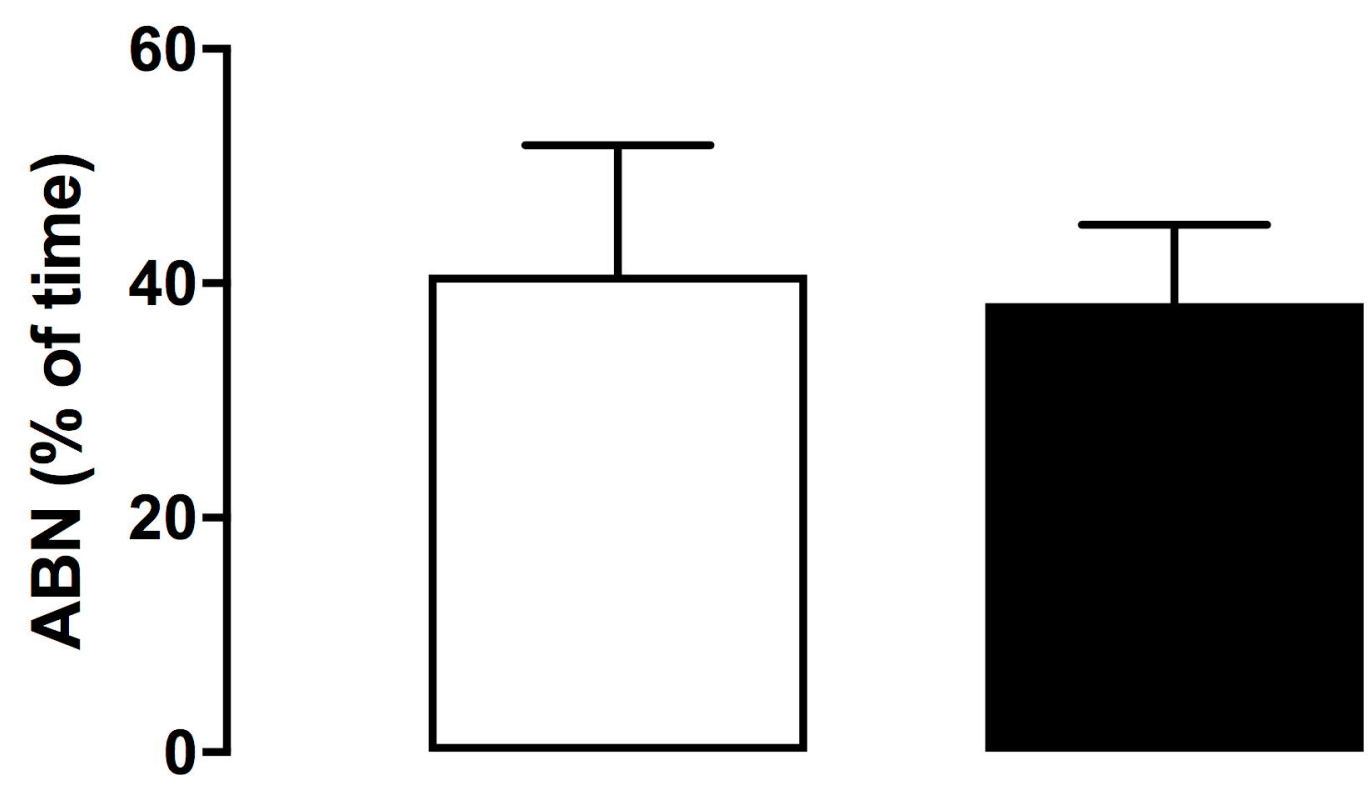